\title{
NUMERICAL INVESTIGATION OF HORIZONTAL MAGNETIC FIELD EFFECT ON THE FLOW CHARACTERISTICS OF GALLIUM FILLED IN A VERTICAL ANNULUS
}

\author{
Vahid Ahmadpour ${ }^{1, \star}$, Sajad Rezazadeh${ }^{1}$, Iraj Mirzaei², Amir Hossein Mosaffa ${ }^{3}$
}

\begin{abstract}
In the present numerical study, the effect of an external horizontal magnetic field on the natural convection of an electrically conducting molten metal (gallium) inside a vertical cylindrical crucible has been investigated. The effect of the external magnetic field is evaluated on the flow pattern and also the temperature field of molten gallium in the mold with an aspect ratio of $A=1.0$ and a radii ratio of $\lambda=3.0$. A series of simulations are carried out for Hartmann numbers of 0, 22.5, 112, and 167 and Rayleigh numbers of 104, 105, and 106. The obtained results show that for a given Rayleigh number, increasing the Hartmann number suppresses convection flows in all directions with different intensities. Moreover, it was found that the employed horizontal magnetic field leads to vanishing the axisymmetric pattern of flow structures. This is due to the formation of Roberts and Hartmann layers near the walls parallel $\left(0^{\circ}\right.$ and $\left.180^{\circ}\right)$ and normal $\left(90^{\circ}\right.$ and $\left.270^{\circ}\right)$ to the magnetic field, respectively. Additionally, it is found that the presence of the magnetic field results in the reduction of convection heat transfer. This reduction is lower in the $90^{\circ}$ and $270^{\circ}$ directions due to the development of Roberts layers near the walls parallel to an external magnetic field. Finally, the numerical results have been validated against the published reliable data.
\end{abstract}

\section{Keywords: Magnetic Field, Lorentz Force, Electric Field, Natural Convection, Annulus}

\section{INTRODUCTION}

In order to control the product quality in the casting process, it is necessary to control many parameters including composition, cooling rate, boundary conditions, body and external forces, and the temperature field of the molten metal. It is proved that the natural convective flows by the temperature gradients are the source of most defects in solidified part. The nature of these flows is so that play a significant role in solid/liquid front morphology and solidified structure. When natural convection in the melt is weak, only a flat solidified front can be formed in a mushy zone and this means a solidified with less residual thermal stresses [1]. Hence, controlling unwanted natural convection-induced flows in molten metal is crucial. In practice, it is possible to overcome these limitations partially by several methods such as; rotating crucibles, reduced gravity media, and applying an external constant or traveling magnetic fields. An interesting solution is applying an external magnetic field to suppress the buoyancy-driven flows which are referred to as Magnetohydrodynamics (MHD) problems in the literature. The physics of the problem is hidden through the interaction of a magnetic field and a conductive fluid flow. This interaction develops a force known as the Lorentz force which depends on magnetic field orientation, strength, fluid thermophysical properties, and fluid particle velocity [2]. The convective motion of the electrically conducting melt in a magnetic field generates electrical currents, which interact with the magnetic field resulting in a damping force on the flow. The purpose of this investigation is to simulate the interaction of horizontal magnetic field and the conductive molten gallium inside a three-dimensional annulus shape crucible with considering induced electric fields numerically.

Various numerical and experimental studies were performed on the interaction of magnetic fields and natural convection flows. Oreper and Szekely [3] studied transient development of the fluid flow field and the temperature distribution in a rectangular cavity in the presence of an imposed magnetic field. It was found that by imposing a high magnetic field the effect of the melt front velocity on the convective heat transfer can be minimized. Okada and Ozoe [4] reported experimentally heat transfer rate of natural convection of gallium in a cube under an external magnetic field in either $\mathrm{x}, \mathrm{y}$, or $\mathrm{z}$-direction. They clarified that heat transfer rate depends on the direction of the magnetic field and also the average heat transfer rate decreases with the strength of the magnetic field. Natural This paper was recommended for publication in revised form by Regional Editor Erman Aslan

${ }^{1}$ Department of Mechanical Engineering, Urmia University of Technology, Urmia, Iran,

${ }^{2}$ Department of Mechanical Engineering, Urmia University, Urmia, Iran

${ }^{3}$ Department of Mechanical Engineering, Azarbaijan Shahid Madani University, Tabriz, Iran

${ }^{*} E$-mail address: v.ahmadpour@yahoo.com

Orcid id: 0000-0003-0554-056X, 0000-0002-9436-3798, 0000-0003-0907-1369, 0000-0003-2755-8963

Manuscript Received 13 April 2019, Accepted 27 June 2019 
convection of the liquid metal in a cube in a wide range of the Hartmann number was studied by Tagawa and Ozoe [5-6] numerically and experimentally. Their results showed that for $\mathrm{Ha} \geq 50$, the average Nusselt number decreased gradually. They also examined the effect of the electro-conductivity of the enclosure wall. The effect of axial magnetic field on the melt convection in a Czochralski crystal growth has been numerically studied by Fukui et al. [7]. Akamatsu et al. [8] investigated detailed two and three-dimensional numerical analyses on a system with three magnetic field which have different directions.

Gorbunov [9] experimented to study the effect of the thermoelectric current under a uniform magnetic field for molten alloy. The obtained results indicate that the thermoelectric effect can be observed when the large temperature difference (about $200{ }^{\circ} \mathrm{C}$ ) and the large thermoelectric coefficient exist in the liquid metal. This phenomenon is hard to achieve in laboratory conditions. Kaneda et al. [10] performed a numerical study on the effect of the thermoelectric current (Seebeck effect) inside the liquid metal under a uniform magnetic field parallel to the heated and cooled walls. They showed that when the Seebeck effect operates, an additional current is induced spontaneously from the cold wall to the hot wall in the liquid metal. Ezaki et al. [11] studied melt flow in the model system of the continuous steel casting process with an application of various magnetic field directions numerically. Three different coil locations were considered to have X-, Y-, or Z-directional magnetic fields. The axial magnetic field appears to suppress the melt convection flow most effectively. Juel et al. [12] presented the results of an experimental and numerical study of the effects of a steady magnetic field on sidewall convection in molten gallium. The magnetic field was applied in a direction that was orthogonal to the main flow which reduces the convection and good agreement was found for the scaling of this effect with the relevant parameters. In a similar work, Hof et al. [13] carried out experiments to study the effect of different directions of a constant magnetic field on convection flow in a rectangular enclosure filled with gallium. Their results showed that the transverse field has a stronger damping effect than the longitudinal one.

In another research, $\mathrm{Xu}$ et al. [14] carried out experiments to study the thermally induced convection of molten gallium in the magnetic field in a three-dimensional rectangular box. They compared the results with a numerical method based on a weak induced electric field. The results showed that natural convection is suppressed with an imposed magnetic field and the magnetic damping effect increases with an increase in the applied field strength. The effects of $\mathrm{Re}, \mathrm{Ri}$, and Ha numbers have been studied numerically by Dash and Singh [15]. They supposed a three-dimensional swirling flow in an annulus that was subjected to axial temperature gradient and influence of the axial magnetic field. Sarris et al. [16] studied the transient and turbulent natural convection flow in an electrically conductive fluid numerically. In this work, the vertical magnetic field was exerted on a vertical cylinder. They found that the effect of the magnetic field amount on the cooling rate of the cylinder wall depends on the Rayleigh number.

Recently Rashidi et al. [17] investigated the effect of a magnetic field on the mixed heat transfer in a channel with a sinusoidal wall filled with $\mathrm{Al}_{2} \mathrm{O}_{3}$ nanofluid. They reported an enhancement of heat transfer in the presence of the magnetic field. Sampath and Zabaras [18] considered the buoyancy, surface tension, and electromagnetic forces in melt flow, during the solidification process. The magnetic field influence on melt flow has been studied for both normal and low gravity enticement. It is demonstrated that the application of a strong magnetic field significantly damps the melt flow. An experimental investigation of solidification and melting of gallium in a cube in presence of a constant magnetic field was performed by Charmchi et al. [19]. They simulated the numerical model with a strong induced electric field and for validating the obtained results; they compared them with experimental data. They concluded that a strong magnetic field reveals different 3D flow structures in the melt region.

Other numerical investigations about the magnetic field effect on melt convection flow have been done by Sankar et al. [20]. In their work, the effect of magnetic field on the flow pattern in a cylindrical annular enclosure has been studied. The effect of the magnetic field direction, strength, and aspect ratio of the annulus also was studied numerically. In the case of the horizontal magnetic field, they also ignored the effect of the induced electric field. Wrobel et al. [21] have studied the effect of a strong magnetic field gradient on the natural thermal convection of a paramagnetic fluid in a three-dimensional annulus experimentally and numerically. The value of the Rayleigh number was approximately $\mathrm{Ra}=1.5 \times 105$. The results showed that a high magnetic field can be used to enhance and 
also suppress the thermal convection of paramagnetic fluid. Afrand et al. [22] investigated a three-dimensional numerical method to analyze the natural convection in an inclined cylindrical annulus containing molten potassium under a magnetic field. They concluded that a magnetic field can generate an electric potential and thus reduce the value of the Lorentz force. Therefore, the electric potential can generate a harmful impression on the suppressing effect of the magnetic field. The effect of an axial magnetic field on the flow produced by counter-rotation of the top and bottom disks in a truncated conical enclosure filled with liquid metal is studied by Bendjaghlouliet al. [23]. It was observed that the Reynolds number is increased, the axisymmetric basic state loses stability and giving an asymmetric mode $m=1$. It is also found that the primary. Very recently Bakar et al. [24] studied the effect of magnetic field on fluid flow and heat transfer in a two-dimensional square cavity numerically. The streamlines and isotherm plots and the variation of Nusselt numbers on hot and cold walls were presented.Zahmatkesh and Ardekani [25] analyzed the effect of magnetic field orientation on free convection of several water-based nanofluids in a square porous cavity. Inspection of the results demonstrates that increase in the magnetic field strength deteriorates the heat transfer rate.

Even though one of the most important shapes of molds is annulus enclosure, but there is scarcity about the application of magnetic fields and its effect on the solid/liquid phase change of metal in this type of cavity. The goal of the present study, therefore, is to evaluate the effect of the external magnetic field by considering induced electric fields on the flow and temperature fields of an electrically conducting molten metal in a vertical annulus. The effects of Hartmann and Rayleigh numbers on the induced electric field, flow pattern, and temperature distribution in molten metal have been investigated. This study explains how a horizontal magnetic field damps unwanted threedimensional convection flows in this cylindrical crucible. Finally, the numerical results were validated with available experimental data and numerical calculations.

\section{THEORY PHYSICAL MODEL AND ASSUMPTIONS}

The geometry of considered model in this numerical study is depicted schematically in Fig. 1. The proposed model three-dimensional flow simulation in a cylindrical annulus which its height and width are given by $\mathrm{H}$ and $\mathrm{D}$, respectively. It contains an electrically conducting molten metal. The inner wall (colder side) temperature set to $\mathrm{T}_{\mathrm{C}}$ and the outer wall (hotter side) is kept at $\mathrm{T}_{\mathrm{H}}$ (so that $\mathrm{T}_{\mathrm{H}}>\mathrm{T}_{\mathrm{C}}$ ). The selection of $\mathrm{T}_{\mathrm{C}}$ and $\mathrm{TH}$ for inner and outer walls is due to consideration of the solidification process for future studies. The other two surfaces (upper-lower) are thermally insulated with rigid boundaries. Temperature gradients by two vertical walls cause density changes in molten metal and in presence of gravitational forces buoyancy flows are driven. In this problem a uniform external magnetic field $\mathrm{B}_{0}$ also is applied in direction of $\mathrm{x}$. The resulting natural-MHD convection flows in electrically conducting melt in the presence of gravitation-magnetic field are governed by the equations of mass, momentum, energy, and electrical potential. To derive governing equations the following assumptions has been made:

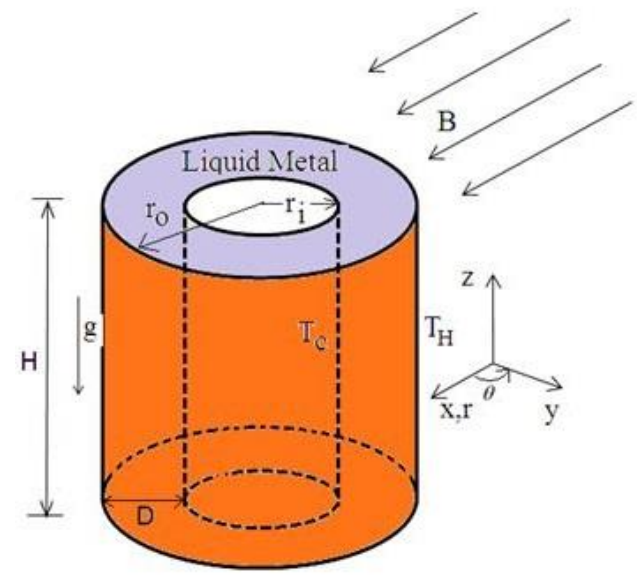

Figure 1. The physical model and the boundaries 
1-The melt behaves like a Newtonian and incompressible fluid.

2-The flow in the cavity is considered to be laminar and steady.

3-The thermo-physical properties of the melt are temperature independent except for density of melt that employs the Boussinesq approximation for density changes due to temperature gradients, $\rho=\rho_{0}\left(1-\beta\left(T-T_{0}\right)\right)$, Where, $\beta$ is volumetric thermal expansion, $\rho_{0}$ and $T_{0}$ are reference density and temperature, respectively.

4-The heat dissipation and Joule heating are neglected.

5- The induced magnetic fields are assumed to be small.

Invoking the assumptions, the governing equations namely, mass, momentum, energy and electrical potential equations can be expressed as [2]:

$$
\begin{gathered}
\nabla \cdot(\rho \vec{V})=0 \\
\rho(\vec{V} \cdot \nabla) \vec{V}=-\nabla P+\mu \nabla^{2} \vec{V}+\vec{F}_{b}+\vec{F}_{E M} \\
(\vec{V} \cdot \nabla) T=\alpha \nabla^{2} T \\
\nabla^{2} \varphi=\nabla \cdot\left(\vec{V} \times \vec{B}_{0}\right)=\vec{V} \cdot\left(\nabla \times \vec{B}_{0}\right)+\vec{B}_{0} \cdot(\nabla \times \vec{V})
\end{gathered}
$$

where the source terms $\vec{F}_{b}$ and $\vec{F}_{E M}$ represent the buoyancy and magnetic forces in the melt, respectively. The symbols $\nabla$ and $\nabla^{2}$ are related to gradient and Laplacian operators. Here, also it was assumed that the induced magnetic field throughout the melt is negligible compared to the constant external magnetic field of $\vec{B}_{0}$ and applied magnetic field does not vary with time. It is worthy to note that this assumption is valid for the fluids with law magnetic Reynolds number, $R_{m}=\mu \sigma U_{0} D$, where $\mu_{0}, \sigma, U_{0}, D$ denote the magnetic permeability, electric conductivity of the molten metal, reference velocity and characteristic length. The reference velocity could be obtained via the $U_{0}=\sqrt{g \beta D\left(T_{H}-T_{C}\right)}$. However, for the most liquid metals, the magnetic Reynolds number is sufficiently small and law- $R_{m}$ model is applicable [1]. Its order of magnitude for present study is $10^{-3}$.

The equations for the electric current density, Lorentz force and induced electric are obtained by:

$$
\vec{J}=\sigma\left(\vec{E}+\vec{V} \times \vec{B}_{0}\right), \quad \vec{F}_{E M}=\vec{J} \times \vec{B}_{0}, \quad \vec{E}=-\nabla \varphi
$$

The boundary conditions are specified as follows:

$$
\begin{gathered}
\text { At } r=r_{i} \text { and } 0 \leq z \leq H \quad T=T_{C}, u_{r}=u_{\theta}=u_{z}=0 \quad \text { (cold wall) } \\
\text { At } r=r_{0} \text { and } 0 \leq z \leq H \quad T=T_{H}, u_{r}=u_{\theta}=u_{z}=0 \quad \text { (hot wall) } \\
\text { At } z=0, H \text { and } r_{i} \leq r \leq r_{o} \frac{\partial T}{\partial z}=0, u_{r}=u_{\theta}=u_{z}=0 \\
\frac{\partial \varphi}{\partial n}=0, \quad \text { for all walls }
\end{gathered}
$$

Further, in MHD problems, the resulting flows generally depend on some important dimensionless parameters: the Prandtl number, the Rayleigh number, and the Hartmann number. Thus, in this study, some results also will discuss through these three parameters and defined as: 


$$
R a=\frac{g \beta \Delta T D^{3}}{v \alpha}, \quad \operatorname{Pr}=\frac{v}{\alpha}, \quad H a=D B_{0}
$$

where, $D=r_{0}-r_{i}$ is annulus characteristic length for defining Rayleigh and Hartmann numbers. Additionally, in the present MHD natural-convection flow, the results validated by comparison the most important flow and heat transfer quantity, namely "Nusselt number". Generally, the relation for Nusselt number is:

$$
N u(\theta, z)=-\left.\frac{\partial T^{*}}{\partial r}\right|_{r=r_{i}, r_{o}}
$$

where $N u(\theta, z)$ is the local Nusselt number at the inner and outer walls and $T^{*}$ calculated from:

$$
T^{*}=\frac{T-T_{H}}{T_{H}-T_{C}}
$$

while the average (i.e. averaged axially and azimuthally) Nusselt numbers at the inner and outer walls were calculated, as:

$$
\overline{N u}=\frac{1}{2 \pi H} \int_{0}^{2 \pi} \int_{0}^{H} N u(\theta, z) \partial
$$

\section{NUMERICAL PROCEDURE AND SIMULATION DETAILS}

An in-house code is developed by using FORTRAN software to solve the governing equations. The Lorentz force is considered in the momentum equation as an external force term and all the described equations solved using the control volume approach. Pressure-velocity coupling in the momentum equation is handled by the SIMPLE scheme [26]. The buoyancy and diffusion terms are discretized with a second-order central difference scheme while the second-order upwind differencing is preferred for convective terms for numerical stability. The QUICK scheme is employed in the solution of the energy equation. The upwind scheme was used for the solution of the electrical potential equation. The governing equations are solved by using boundary conditions. The convergence is declared when the maximum relative change between two consecutive iteration levels fell less than $1 \times 10-8$ for continuity and momentum and $1 \times 10-8$ for energy and electrical potential. Various series of three-dimensional grid systems tested to ensure the grid independence, depending mainly on the Rayleigh number of flow, and finally, the optimum mesh size is selected to run the calculations. Figure $2 \mathrm{a}$ indicates the mesh grid that is used in the current simulation. Variations of the axial component of velocity evaluated in three grid size of $30 \times 81 \times 50,50 \times 121 \times 50$, and $60 \times 161 \times 60$ at $\mathrm{z}=$ 0.025 along the $x$-direction, and the results are indicated in Fig. 2b. Variation of the computed vertical component of velocity at $\mathrm{z}=0.025$ along $\mathrm{y}$-direction for $50 \times 121 \times 50$ and $60 \times 161 \times 60$ grid sizes found to be negligible. Accordingly, the $50 \times 121 \times 50$ grid is found suitable for calculations.

To prove the accuracy and performance of the present numerical model, results are compared with the available experimental and numerical models. In the absence of a magnetic field, the present simulations are compared with that of the experimental study of Wrobel et al. [21] and the numerical results of Afrand et al. [22]. They investigated convection in an annulus between two vertical co-axial cylinders resulting from gravitational and magnetic environments. A comparison of the average Nusselt numbers values versus the Rayleigh number on the hot wall in the case of the vertical annulus are shown in Fig. 3. As it is clear, there is a good agreement with the benchmarks data. 


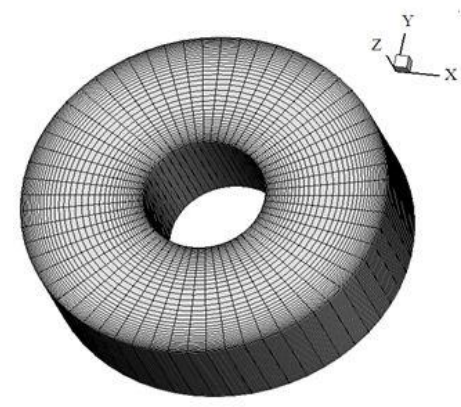

a)

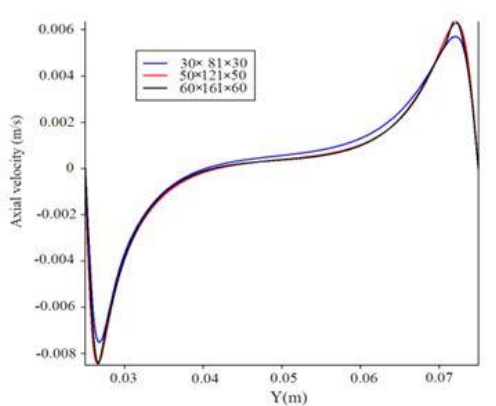

b)

Figure 2. a) The mesh grid that used in calculations $(50 \times 121 \times 50)$ and $b)$ grid independence study for axial component of velocity for $\mathrm{Ra}=105, \operatorname{Pr}=0.0244, \mathrm{Ha}=112, \mathrm{~A}=1$, and $\lambda=3$

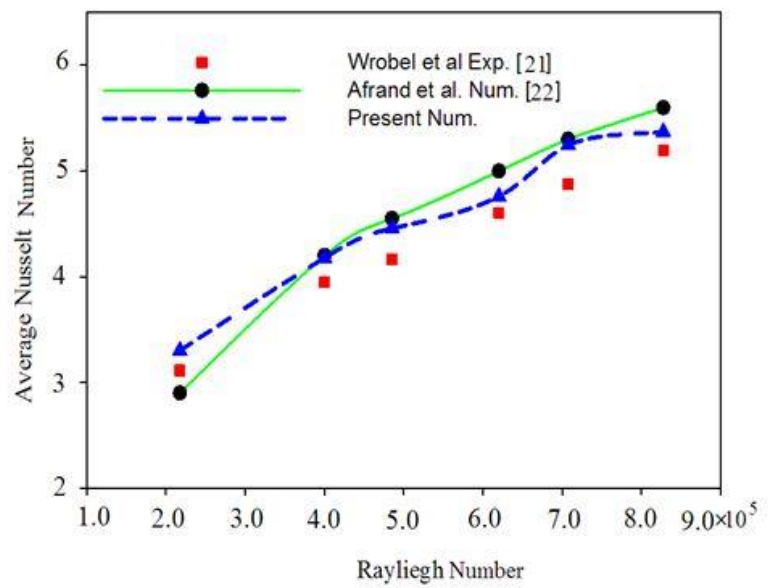

Figure 3. Calculated average Nusselt

To further insurance, the obtained numerical results are also validated in presence of the external magnetic field. The results from present model are compared with that of numerical study of Afrand et al. [22]. Figure 4 shows Nusselt numbers versus Prandtl number for different Hartmann numbers. It is clearly delineated in the figure that agreement between the 3D results is very good. Overall, the derived results show that present numerical model gives a quite good agreement compared to available data.

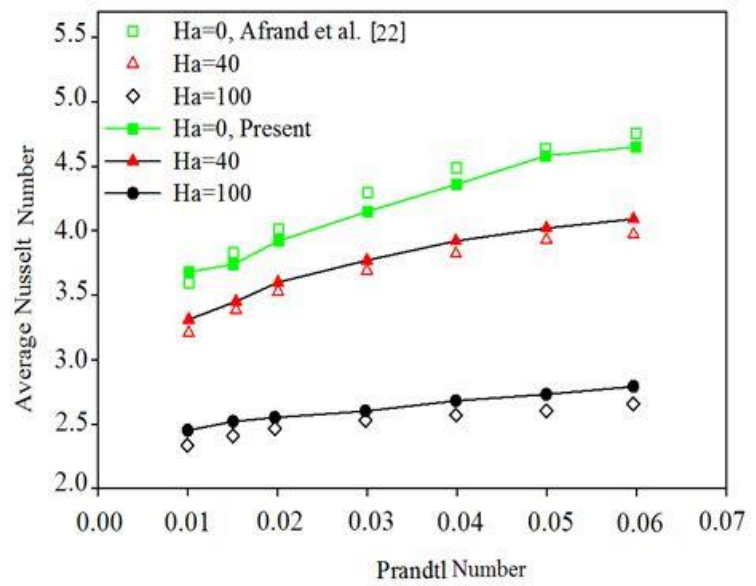

Figure 4. Comparison of present calculated average Nusselt number with results of Afrand et al. [22] for $\mathrm{Ra}=10^{5}$, $\lambda=2.0$ 


\section{RESULTS AND DISCUSSION}

A systematic study is performed to evaluate the effect of some vital parameters on the forced convection of liquid gallium inside the annulus. Table 1 lists the dimensions of the test case that was selected to study and the physical properties of gallium are tabulated in Table 2. The results are presented in three sections: First, the pure heat convection in the cavity is represented. Second, the effect of the temperature difference between the inner cold wall and the outer hot wall on the flow and heat transfer process is studied by varying the Rayleigh number. Third, the effect of the external magnetic field on the buoyancy effect is investigated versus the Hartmann number. The temperature distribution, the flow, and electrical fields induced Lorenz forces in the melt and the average Nusselt number at the hot and cold walls is studied for the considered parameters with more details. The results have been considered with and without induced electrical field effects. The Rayleigh number has been ranged from 104 to 106. Additionally, four values of magnetic field strength $(0.0 \mathrm{~T}, 0.01 \mathrm{~T}, 0.05 \mathrm{~T}$, and $0.075 \mathrm{~T}$ ) are considered in calculations. The Hartmann number (which denotes the relative strength of Lorentz force to viscous force), for the mentioned magnetic strengths, can be calculated as $\mathrm{Ha}=0,22.5,112,167$. These values are chosen because the magnetic fields associated with these numbers could be realized with permanent magnets. The Prandtl number of gallium is assumed to equal 0.0244 .

Table 1. Test case dimensions

\begin{tabular}{|l|c|}
\hline Inner, outer radius, ri, ro(m) & $0.025,0.075$ \\
\hline Annulus height, $\mathrm{H}(\mathrm{m})$ & 0.05 \\
\hline Aspect ratio, $\mathrm{A}=\mathrm{H} /(\mathrm{ro}-\mathrm{ri})$ & 1.0 \\
\hline Radii ratio $\lambda=\mathrm{ro} / \mathrm{ri}$ & 3.0 \\
\hline
\end{tabular}

Table 2. Thermo-physical properties of the gallium [19]

\begin{tabular}{|l|c|c|}
\hline \multicolumn{1}{|c|}{ Material Property } & Value & Unit \\
\hline Density & 6094.7 & $\mathrm{~kg} / \mathrm{m}^{3}$ \\
\hline Heat capacity & 397.6 & $\mathrm{~J} / \mathrm{kg} \mathrm{K}$ \\
\hline Thermal diffusivity & $1.29 \times 10^{-5}$ & $\mathrm{~m}^{2} / \mathrm{s}$ \\
\hline Viscosity & $1.92 \times 10^{-3}$ & $\mathrm{~kg} / \mathrm{m} \mathrm{s}$ \\
\hline Electrical conductivity & $3,846,154.1$ & $1 / \mathrm{m}$ \\
\hline Thermal expansion coefficient & $1.27 \times 10^{-4}$ & $1 / \mathrm{K}$ \\
\hline Prandtl number & 0.0244 & - \\
\hline
\end{tabular}

\section{LIMITING CASE OF PURE THERMAL CONVECTION (HA=0)}

In the case of pure natural convection, the temperature distributions and flow structures are represented for different Rayleigh numbers. Figure 5 demonstrates the results in a typical vertical cross-section. As can be seen, at Rayleigh number $\mathrm{Ra}=10^{4}$, isotherms inclination is small and temperature gradients are nearly vertical. Indeed, because of weak convection isotherms are similar to conduction heat transfer mode.

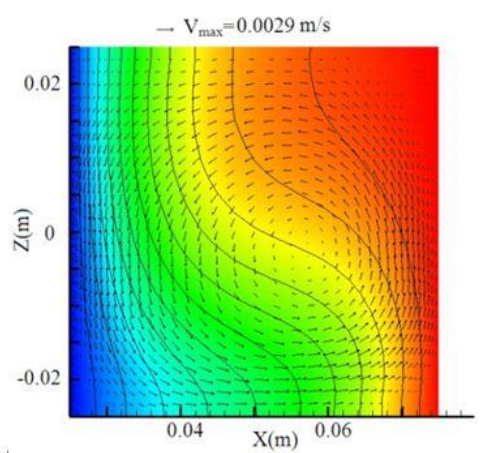

a) $\mathrm{Ra}=10^{4}$

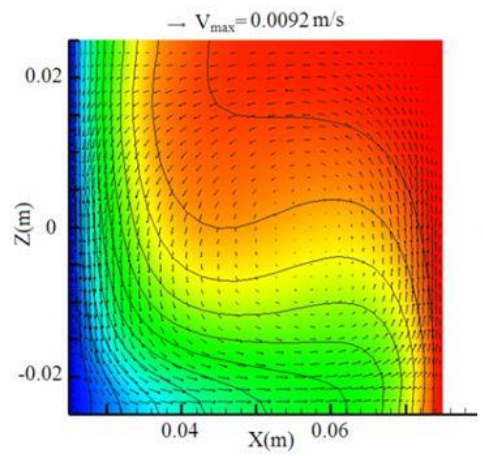

b) $\mathrm{Ra}=10^{5}$

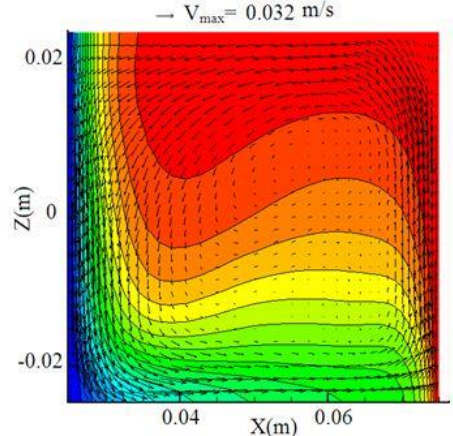

c) $\mathrm{Ra}=10^{6}$

Figure 5. Vertical cross-section of temperature distributions and flow structures at a) $10^{4}$, b) $10^{5}$ and c) $10^{6}$ 
At a higher Rayleigh number (106), thermal boundary layers grow and elongate in the horizontal direction, because in this case, the convection mode is the dominated mode of heat transfer. As mentioned before, in absence of an external magnetic field the flow in the annulus is axisymmetric and profiles in vertical planes are similar.
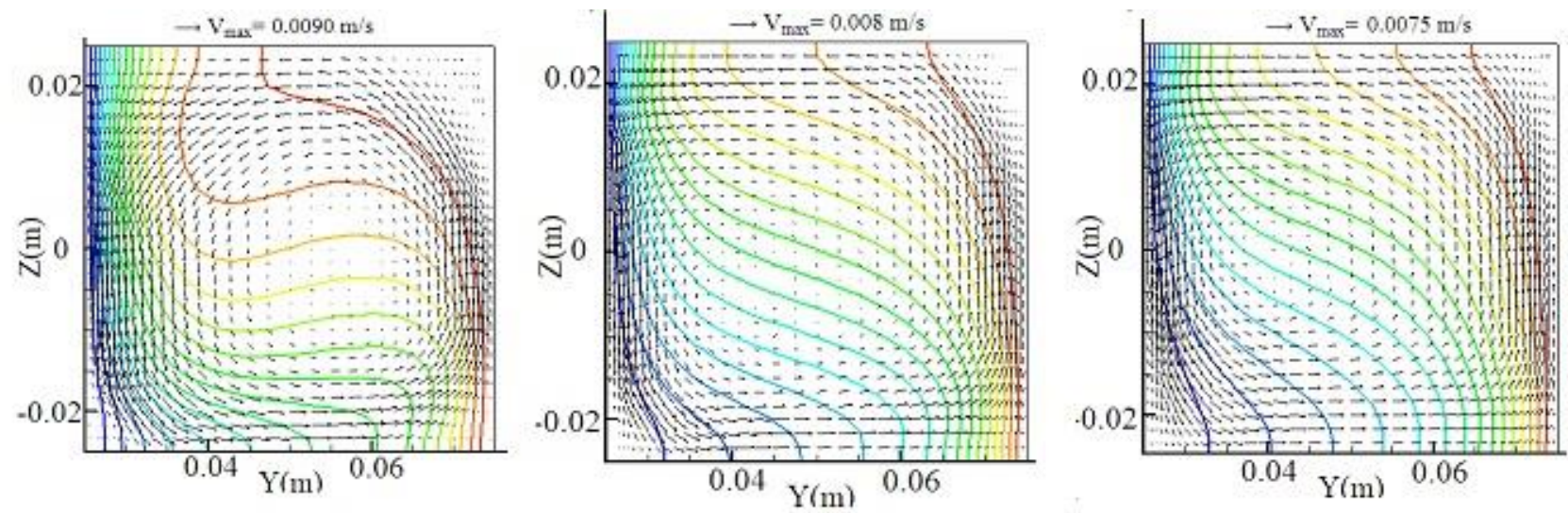

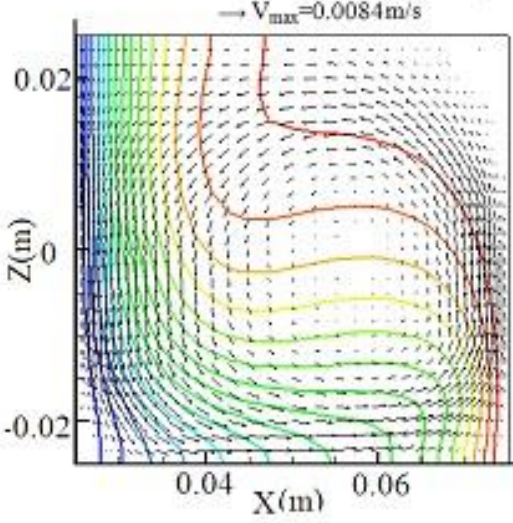

a) $\mathrm{Ha}=22.5$

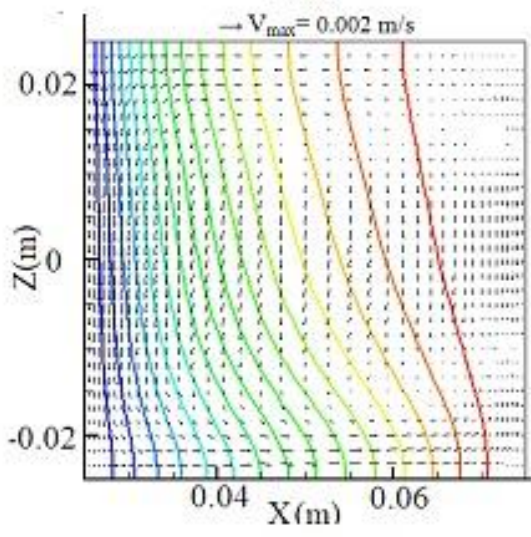

b) $\mathrm{Ha}=112$

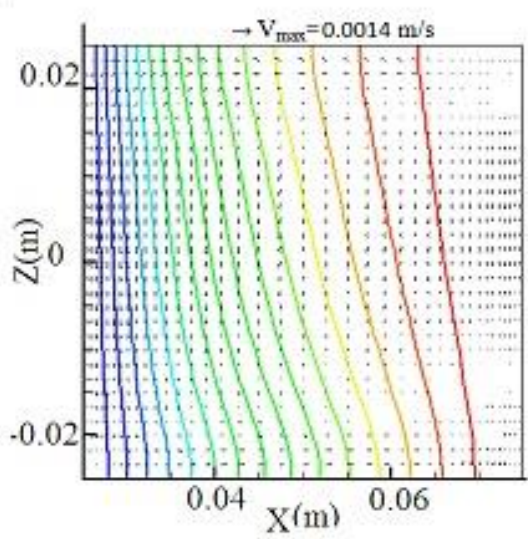

c) $\mathrm{Ha}=167$

Figure 6. Effect of the magnetic field strength on temperature field and velocity distribution for $\mathrm{Ra}=10^{5}$ in the different cross sections.

\section{EFFECT OF MAGNETIC FIELD STRENGTH}

In order to investigate the influence of constant horizontal magnetic field on flow and heat transfer of gallium in annulus cavity, simulations were conducted under various levels of magnetic field strengths. For the described test case, four values of Hartmann number $(\mathrm{Ha}=0,22.5,112,167)$ are chosen because the magnetic fields associated with these numbers could be realized with permanent magnets. On the other hand, these values of Hartmann numbers lead to two important phenomena: -the flow is affected significantly by the applied magnetic field. - the melt flow is not completely damped and there are interactions between buoyancy and electromagneticallydriven flow that can be studied [18]. It should be said that all the results in this section are presented for Rayleigh number $\mathrm{Ra}=10^{5}$.

In Fig. 6 isotherm and the corresponding velocity, distributions have been presented for different magnetic strengths. As can be observed, the general damping effects of convection structures in the y-z plane are significantly more effective compared to the $\mathrm{x}-\mathrm{z}$ plane. However, simulations show a maximum difference of $(81 \%)$ in the maximum velocity magnitude in the mentioned cross-sections. More inspection of isotherms and velocity field in the y-z plane shows completely different behavior for liquid gallium. It can be observed from Fig. 6 that the convection structures play still a significant role in this cross-section, even for the magnetic strength of Ha=167. To explain the apparent discrepancy of results in the $y-z$ plane, 3D distributions of Lorentz force, velocity, and induced electric fields are depicted in Fig. 7. 


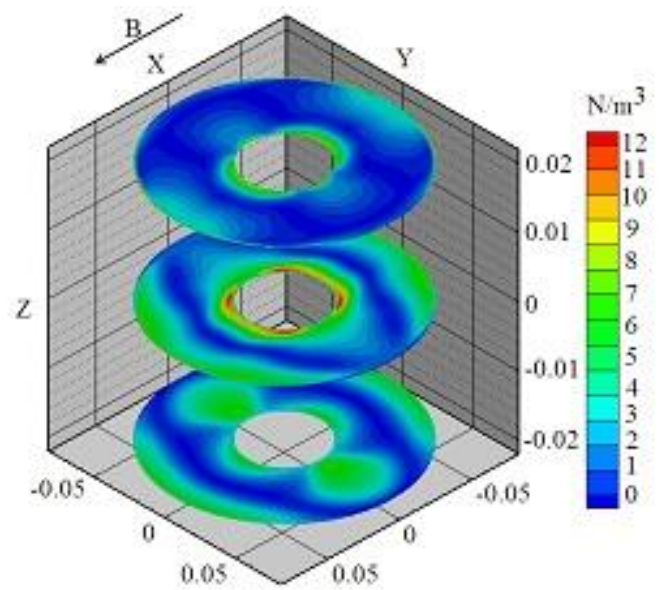

(a)

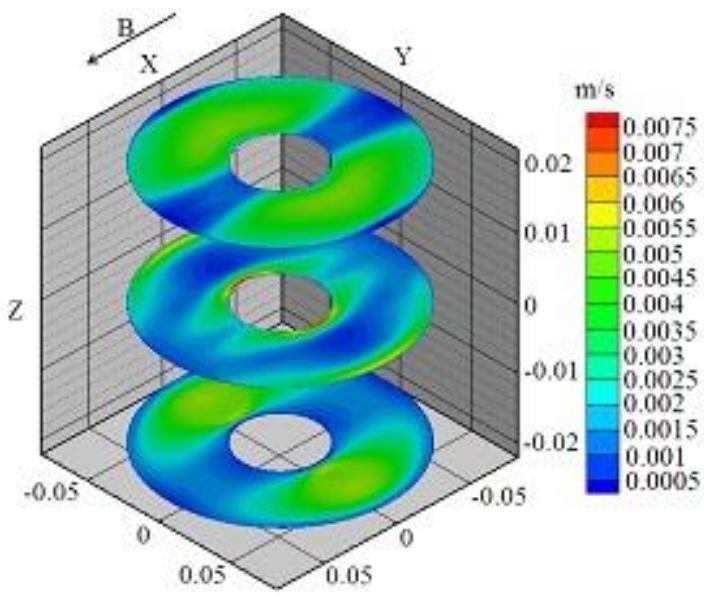

(b)

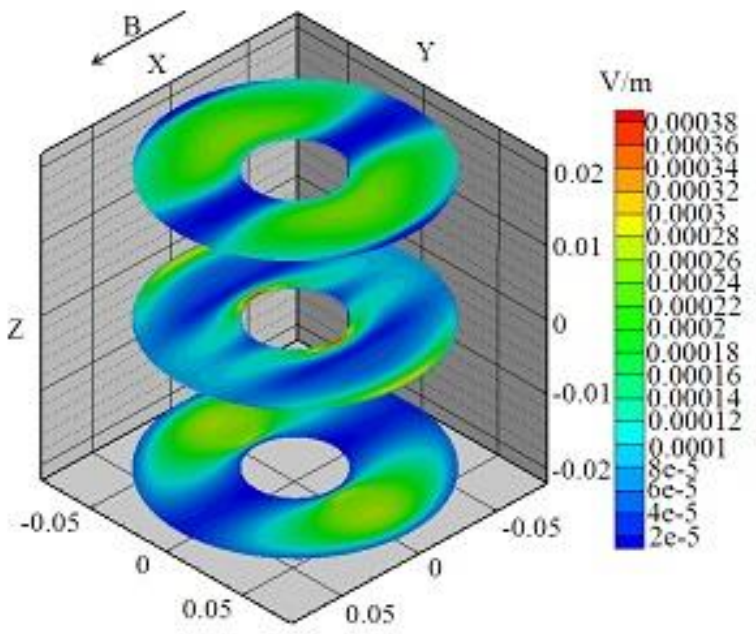

(c)

Figure 7. 3D distribution of magnitude of Lorentz force a), velocity field $b$ ), and induced electric field c) for $R a=10^{5}$ and $\mathrm{Ha}=112$

The contours of velocity magnitude in Fig. $7 \mathrm{~b}$ imply that the magnetic field causes the loss of flow axisymmetric pattern. Figures $7 \mathrm{a}$ and $7 \mathrm{c}$ also reveal that the wakes are developed near the cylindrical walls. This is due to the fact that Hartmann and Roberts layers are developed near the walls normal and parallel to the magnetic field, respectively. It is known that for a cylindrical cavity with a horizontal magnetic field, the thicknesses of the Hartmann layer are depended on the azimuthal angle $\theta$ [27]. The induced electric field, suppresses the fluid flow more in both layers, but inside the Hartmann layers, the reduction is larger than in the side layers. The mentioned reduction is lower in the $90^{\circ}$ and $270^{\circ}$ directions, where the induced electric field is maximized, than at $0^{\circ}$ and $180^{\circ}$ where the Lorentz force is maximized. This behavior can be explained by equation (2.4). The induced electric decreases Lorentz force; However, the term of $\left(\vec{V} \times \vec{B}_{0}\right)$ increases Lorentz force. In x-direction $\left(0^{\circ}\right.$ and $\left.180^{\circ}\right)$ the induced electric field reduces to zero because the magnetic field is normal to the direction of $(\nabla \times \vec{V})$ at this section. As a result, it can be seen that Lorentz force is maximized in the $\mathrm{x}-\mathrm{z}$ plane and is negligible in the $\mathrm{y}-\mathrm{z}$ plane. Furthermore, strong convection flow near inner and outer walls of cavity in the y-z plane confirms the above discussion. Analogous results can also be found in [22]. As a general result, the induced electric field causes to reduce Lorentz force in all directions. 
Figures 8 and 9 display axial velocity components along the $\mathrm{x}$ and $\mathrm{y}$ direction in the mid-height of the cavity for different Hartmann numbers, respectively. As can be seen, increasing the magnetic field strength decreases the axial velocity component in x-direction effectively. In Figs. 10 and 11 the non-dimensional temperature profiles are depicted. More inspection of Fig. 10 makes it clear that temperature profiles in $\mathrm{x}$-direction show linear behavior for higher magnetic field strengths. At $\mathrm{Ha}=112$ and 167, the temperature profiles are similar to the results of conduction mode heat transfer. This behavior is consistent with the previous findings that the applied horizontal magnetic field in the $\mathrm{x}$-direction suppresses the flow in the $\mathrm{x}$-z plane more effectively. Thus in Fig. 11, the temperature profiles even at $\mathrm{Ha}=167$ are much more skewed from the conduction profile, especially in the y-direction where an induced electric field is introduced.

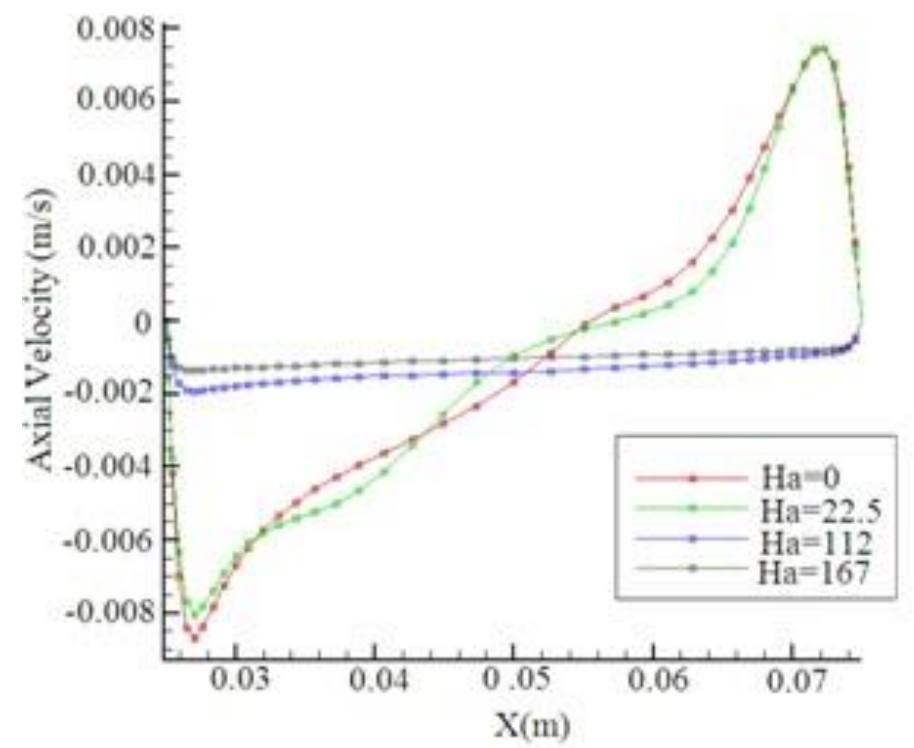

Figure 8. Axial velocity component along X-direction in the mid height of the cavity for different Hartmann numbers

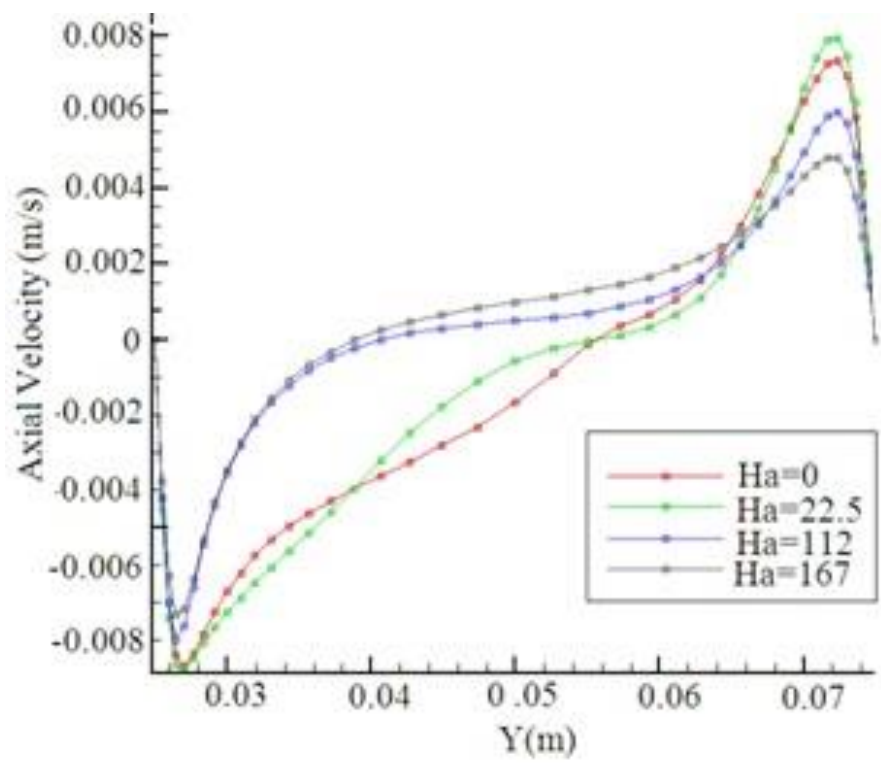

Figure 9. Axial velocity component along Y-direction in the mid height of the cavity for different Hartmann numbers 


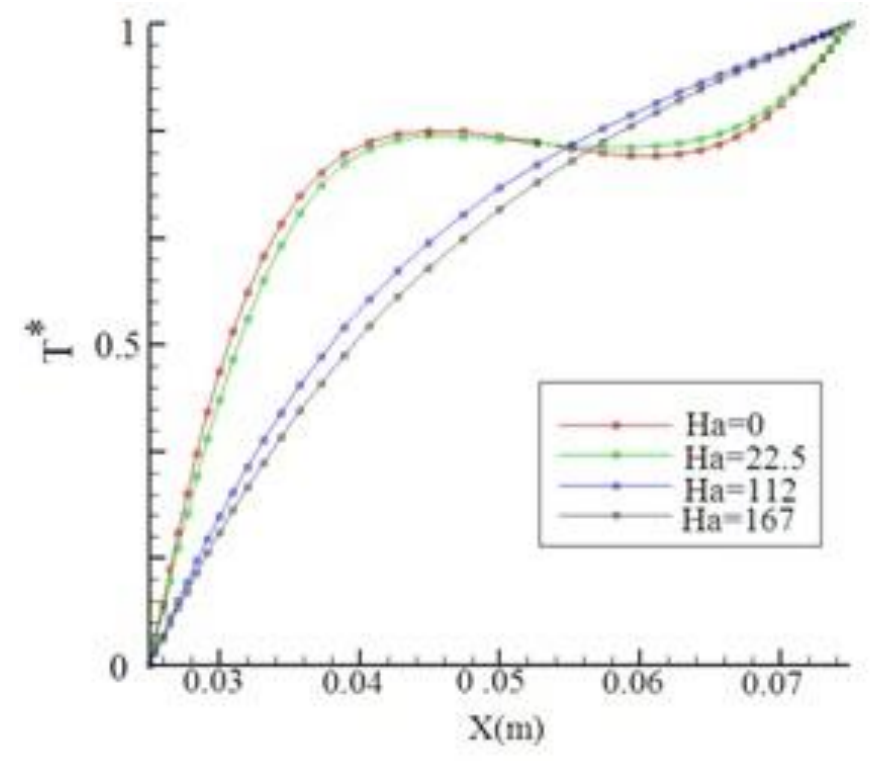

Figure 10. Non -dimensional temperature profiles along X-direction for different Hartmann numbers

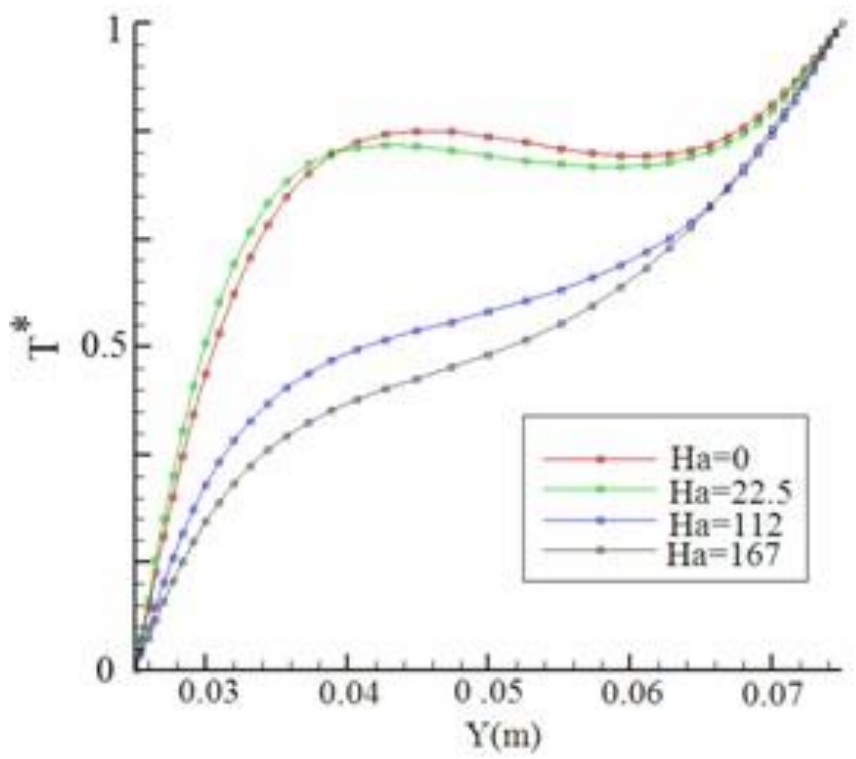

Figure 11. Non -dimensional temperature profiles along Y-direction for different Hartmann numbers

As previously mentioned, the most important flow and heat transfer quantity is the Nusselt number. The distribution of the local and average Nusselt numbers for a range of Hartmann and Rayleigh numbers are studied on the inner (cold) and outer (hot) walls. As Fig. 12 shows, convection heat transfer increases with increasing Rayleigh number, which resulting to an increase of the average Nusselt numbers. But the effect of Hartmann's number is exactly the opposite. That is the presence of the magnetic field results in the reduction of convection heat transfer. This is reasonable to expect, since in the presence of a magnetic field convective flows retarded due to the action of the Lorentz force, and thus, average Nusselt numbers decreases. Here, it should be noted that the negative values of average Nusselt numbers on the cold wall indicate the extraction of heat from the bulk fluid by the inner cold wall. Furthermore, the variation of local Nusselt number at the mid-height of the inner and outer walls is presented for $\mathrm{Ra}=10^{5}$ and $\mathrm{Ha}=112$. As can be seen from Fig. 13, the local Nusselt number is higher near the walls parallel to the direction of the magnetic field (in the $90 \mathrm{o}$ and $270 \mathrm{o}$ directions) where the fluid velocities are higher. 


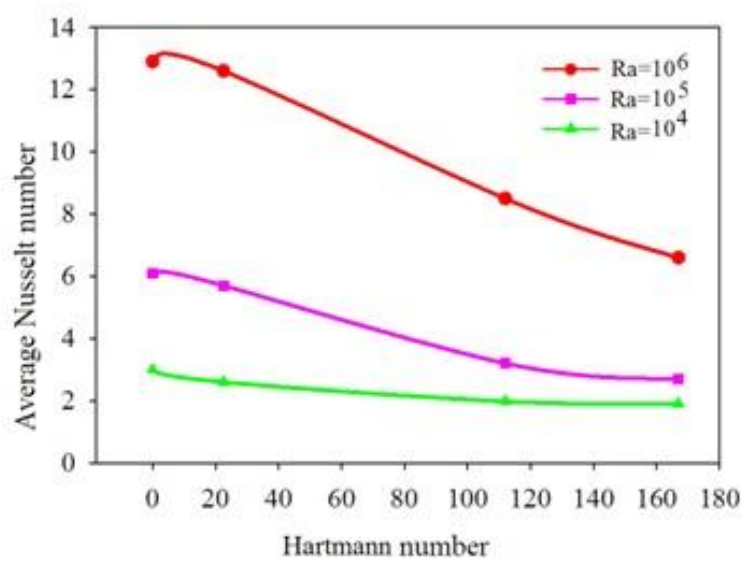

a) Outer wall

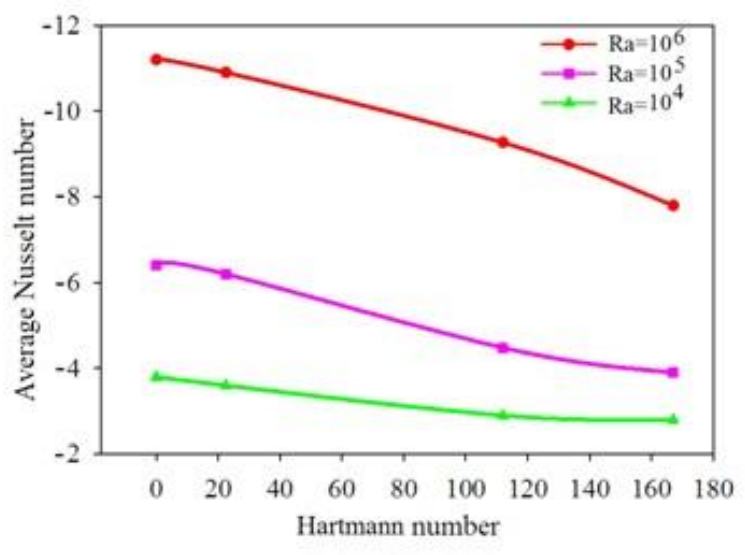

b) Inner wall

Figure 12. Effect of Hartmann and Rayleigh numbers on the computed average Nusselt number

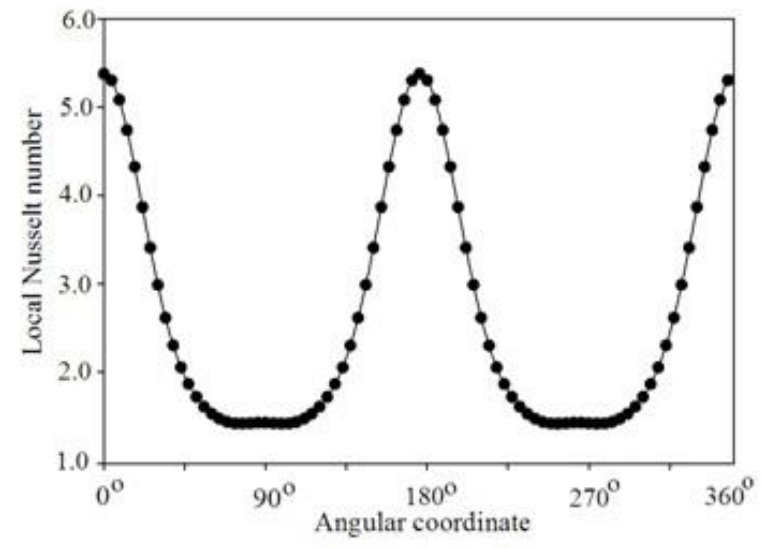

a) Outer wall

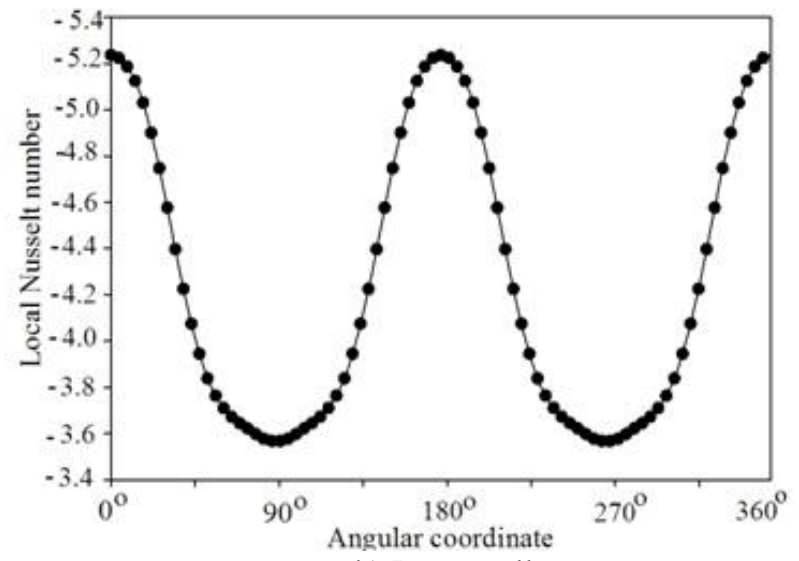

b) Inner wall

Figure 13. Variation of the computed local Nusselt number at the mid height of the inner and outer walls for $\mathrm{Ra}=10^{5}$ and $\mathrm{Ha}=112$

\section{EFFECT OF RAYLEIGH NUMBER}

Rayleigh number represents the strength of buoyancy force in the fluid. Four values of Rayleigh numbers, namely, $10^{4}, 10^{5}$, and 106 are chosen for this study to cover the broad range of the buoyancy force. Figure 14 shows the temperature contours for various Rayleigh numbers in a constant Hartmann number at three different crosssections. In this section, to study the effect of the Rayleigh number on flow pattern and heat transfer characteristics, the $\mathrm{Ha}=167$ has been chosen. As can be seen in Fig. 14a for the small Rayleigh number of $\mathrm{Ra}=10^{4}$, the temperature distribution is smooth and almost parallel to the side walls in the $x-z$ section. In the $y-z$ section, however, the existence of convection was observed from the isotherms. This suggests that the heat transfer is nearly conduction mode with minute local convection effects. However, to completely retard the convection effects, the magnetic field strength should be increased more.

As the Rayleigh number is increased up to $\mathrm{Ra}=10^{5}$, as shown in Fig.14b, the elongation of isotherms in the horizontal direction in the y-z plane can be observed clearly. It confirms previous findings, about the formation of Roberts layers in the walls parallel to the magnetic field direction, which leads to a reduction in Lorentz force.

For $\mathrm{Ra}=10^{6}$ and $\mathrm{Ha}=167$, the curved isotherm in all directions indicates the existence of strong convection in the cavity. This is confirmed in Fig. 14c where the curved isotherms can be observed in the y-z plane. The above temperature distribution in various Rayleigh numbers, suggests that a sufficiently strong magnetic field is required to retard thermal convection in the studied model. Since, the applied horizontal magnetic field strengths are not 
sufficient to dampen the natural convective flows of electrically conducting liquid metals, especially in the walls parallel to the magnetic field. Therefore, it seems to be needed an auxiliary component of the magnetic field in the $y$ or z-direction to suppress the flow more effectively. However, careful use of the present MHD model is needed, as with increasing Rayleigh and Hartmann numbers, limitations arise invalidity of low- $R_{m}$ approximation model [28].

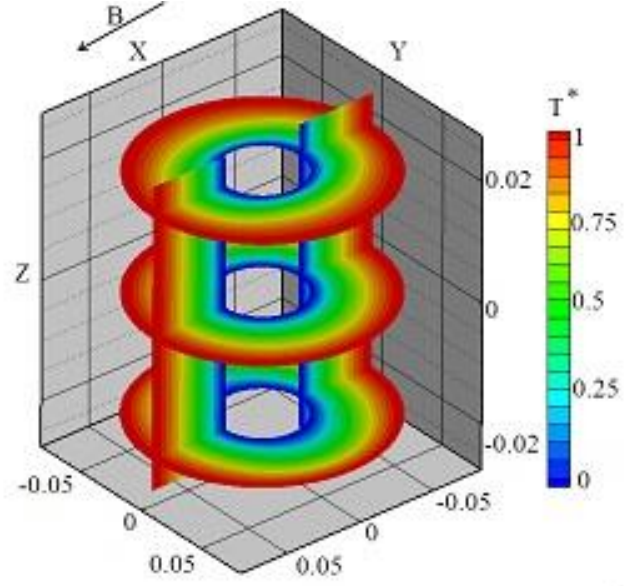

(a) $\mathrm{Ra}=10^{4}$

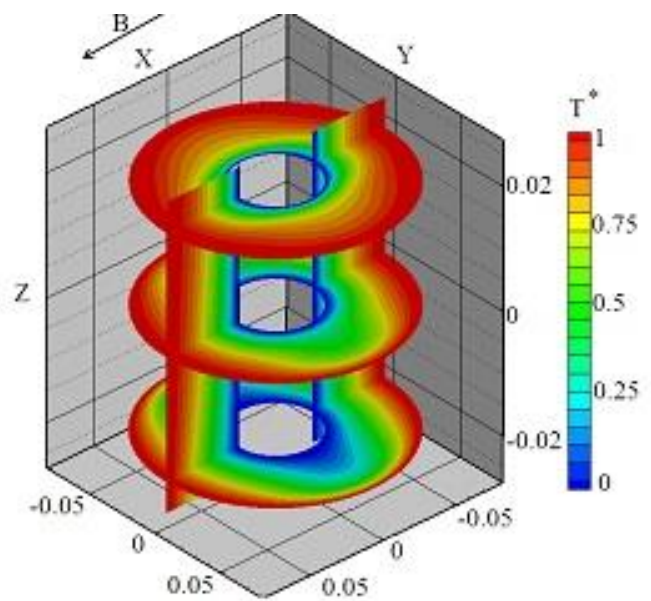

(b) $\mathrm{Ra}=10^{5}$

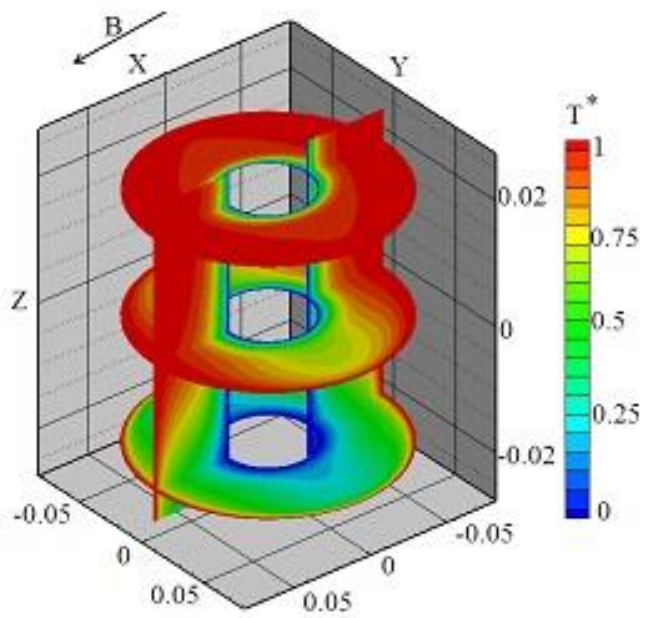

(c) $\mathrm{Ra}=10^{6}$

Figure 14. Effect of Rayleigh number on temperature field for $\mathrm{Ha}=167$

\section{CONCLUSION}

Present study introducing a basic model in a three-dimensional, computational fluid dynamics of thermomagnetic convection of an electrically conducting fluid (gallium) that filled an annulus and subjected to a horizontal constant magnetic field. The effect of the external magnetic field is evaluated on the flow and temperature fields. The results of the present study are compared with different numerical and experimental results available in the literature and are found in good agreement. The obtained results are reported in terms of isotherms, velocity field, induced electric field, and the electromagnetic forces for various Rayleigh and Hartmann numbers. From the results, it is found that for small Rayleigh numbers (104), the natural convection decreases effectively with increasing in the Hartmann. That is, conduction is the dominant heat transfer mode. For high Rayleigh numbers (105 and 106), the influence of magnetic field on natural convection is reduced and it can be seen that the flow structures play a significant role in the heat transfer. The quantitative results, presented in terms of the average Nusselt number, 
indicate that heat transfer increases with increasing external Rayleigh number, resulting to an increase of the average Nusselt number on the walls. The simulations indicate that the flow in the pure thermal convection $(\mathrm{Ha}=0)$ case is axisymmetric. But by applying the horizontal magnetic field, it becomes asymmetric.

It is also found that the presence of the magnetic field results in the reduction of convection heat transfer. This reduction is lower in the $90^{\circ}$ and $270^{\circ}$ directions due to the development of Roberts layers near the walls parallel to an external magnetic field. Additionally, the average Nusselt number decreases with increasing in magnetic field strength. Since the Hartmann layers develop at $0^{\circ}$ and $180^{\circ}$, the magnetic field suppresses the flow and heat transfer in these locations more effectively. It is important to notice that the results of the present threedimensional numerical model are reported with some limitations. The induced magnetic field is assumed to be negligible and Joule heating effects are ignored in the present model. Therefore, it is interesting to take into account these effects to use a comparison with the recent results.

Since in the present study, the thermal boundary condition of the inner and outer cylinder was assumed to be higher than gallium phase change temperature, the solidification of molten metal didn't occur in the mold. The results demonstrated solely for the molten gallium. However, the change in the thermal boundary of the mold induces a more significant mechanism of the effect of magnetic field on the flow, heat transfer, and the solidification process which can be studied in future researches.

\section{NOMENCLATURE}

\begin{tabular}{|c|c|}
\hline$A=H / D$ & Aspect ratio of annulus \\
\hline$\vec{B}_{0}$ & External magnetic field, $\mathrm{Wb} / \mathrm{m}^{2}$ \\
\hline$C_{p}$ & Heat capacity, J/ (kg K) \\
\hline$D=r_{o}-r_{i}$ & Annulus width (reference length), m \\
\hline$\vec{E}$ & Electric field, $\mathrm{V} / \mathrm{m}$ \\
\hline$\vec{F}_{b}$ & Buoyancy force per volume, $\mathrm{N} / \mathrm{m}^{3}$ \\
\hline$\vec{F}_{E M}$ & Magnetic force per volume, $\mathrm{N} / \mathrm{m}^{3}$ \\
\hline$g$ & Acceleration coefficient of gravity, $\mathrm{m} / \mathrm{s}^{2}$ \\
\hline$H$ & Annulus height, m \\
\hline $\mathrm{Ha}$ & Hartmann number \\
\hline$\vec{J}$ & Electric current density, $\mathrm{A} / \mathrm{m}^{2}$ \\
\hline$N u$ & Nusselt number, \\
\hline$\overline{N u}$ & Average Nusselt number, $n$ Surface normal vector, \\
\hline $\operatorname{Pr}$ & Prantle number, \\
\hline$r$ & Radial coordinate, $\mathrm{m}$ \\
\hline$r_{i}$ & Inner radius of annulus, $\mathrm{m}$ \\
\hline$r_{o}$ & Outer radius of annulus, $\mathrm{m}$ \\
\hline$R a$ & Rayleigh number, \\
\hline$R_{m}$ & Magnetic Reynolds number, \\
\hline$T$ & Temperature, $\mathrm{K}$ \\
\hline$T_{C}$ & Inner wall temperature, $\mathrm{K}$ \\
\hline$T_{H}$ & Outer wall temperature, $\mathrm{K}$ \\
\hline$T_{o}$ & Reference temperature, $\mathrm{K}$ \\
\hline$T^{*}$ & Non-dimensional temperature, \\
\hline$U_{0}$ & Reference velocity, m/s \\
\hline$u$ & Velocity component, $\mathrm{m} / \mathrm{s}$ \\
\hline $\mathrm{z}$ & Axial coordinate, $\mathrm{m}$ \\
\hline \multicolumn{2}{|c|}{ Greek symbols } \\
\hline$\alpha$ & Thermal diffusivity, $\mathrm{m}^{2} / \mathrm{s}$ \\
\hline$\beta$ & Thermal expansion coefficient, $\mathrm{K}^{-1}$ \\
\hline$\theta$ & angular coordinate, rad. \\
\hline$\lambda$ & Annulus radial aspect ratio, $r_{o} / r_{i}$ \\
\hline$\mu$ & Viscosity of fluid, kg/ (m.s) \\
\hline$\mu_{0}$ & Magnetic permeability, m/ (s. $\Omega)$ \\
\hline
\end{tabular}




$\begin{array}{ll}v & \text { Kinematic viscosity of fluid, } \mathrm{m}^{2} / \mathrm{s} \\ \rho & \text { Density of liquid metal, } \mathrm{kg} / \mathrm{m}^{3} \\ \rho_{0} & \text { Density at } \mathrm{T}=\mathrm{T}_{\mathrm{o}}, \mathrm{kg} / \mathrm{m}^{3} \\ \sigma & \text { Electric conductivity of liquid metal, }(\Omega . \mathrm{m})^{-1} \\ \varphi & \text { Electric potential, V } \\ \text { Subscripts } & \\ i & \text { Refers to inner radius } \\ o & \text { Refers to outer radius } \\ 0 & \text { Refers to constant value }\end{array}$

\section{REFERENCES}

[1] Davidson P. Introduction to magneto hydrodynamic. Cambridge, UK: Cambridge University Press; 2001.

[2] Müller U, Bühler L. Magnetofluiddynamics in Channels and Containers. Springer; 2001.

[3] Oreper G.M, Szekely J. The effect of an externally imposed magnetic field on buoyancy driven flow in a rectangular cavity. Journal of Crystal Growth 1983;64: 505- 515.https://doi.org/10.1016/00220248(83)90335-4.

[4] Okada K, Ozoe H. Experimental Heat Transfer Rates of Natural Convection of Molten Gallium Suppressed Under an External Magnetic Field in Either the X, Y, or Z Direction. Journal of Heat Transfer 1992;114,1: 107-114. https://doi.org/10.1115/1.2911234.

[5] Tagawa T, Ozoe H. Enhancement of Heat Transfer Rate by Application of a Static Magnetic Field during Natural Convection of Liquid Metal in a Cube. ASME Journal of Heat Transfer 1997;119: $265-271$. https://doi.org/10.1115/1.2824219.

[6] Tagawa T, Ozoe H. Enhanced Heat Transfer Rate Measured for Natural Convection in Liquid Gallium in a Cubical Enclosure Under a Static Magnetic Field. ASME Journal of Heat Transfer 1998;120: $265-271$. https://doi.org/10.1115/1.2825886.

[7] Fukui H, Kakimoto K, Ozoe H. The convection under an axial magnetic field in a Czochralski configuration WIT Transactions on Engineering Sciences 1998;20: 135-144. https://doi.org/10.2495/HT980141.

[8] Akamatsu M, Higano M, Ozoe H. Conventional mode and electrical field in silicon melts under vertical, horizontal, and rotating magnetic field. Numerical Heat Transfer, Part A: Applications 2002; 42:1-2, 33-54. https://doi.org/10.1080/10407780290059413.

[9] Gorbunov L.A. Effect of thermo-electromagnetic convection on the production of bulk single-crystals consisting of semiconductor melts in a constant magnetic field. Magnetohydrodynamics 1987;23 4: $404-407$. OSTI ID: 6164325.

[10] Kaneda M, Tagawa T, Ozoe H. Natural convection of liquid metal in a cube with Seebeck effect under a magnetic field. International Journal of Transport Phenomena 2002; 4,3:181-191. https://doi.org/10.1142/9781860947124_0006.

[11] Ezaki K, Kaneda M, Tagawa T, Ozoe H. Numerical Computation for the Melt Convection of the Model System of Continuous Steel Casting with Various Magnetic Fields.ISIJ International 2003; 43 6, $907-914$. https://doi.org/1010.2355/isijinternational.43.907.

[12] Juel A, Mullin T, Ben Hadid H, Daniel Henry. Magnetohydrodynamic convection in molten gallium. Journal of Fluid Mechanics, Cambridge University Press (CUP), 1999;378: 97-118. https://doi.org/10.1017/S0022112098003061.

[13] Hof B, Juel A, Mullin T. Magneto hydrodynamic damping of convective flows in molten gallium. Journal of Fluid Mechanics 2003; 482: 163-179.

[14] Xu B, Li B.Q, Stock D.E. An experimental study of thermally induced convection of molten gallium in magnetic fields. International Journal of Heat and Mass Transfer, 2006;49: 2009-2019. https://doi.org/10.1016/j.ijheatmasstransfer.2005.11.033.

[15] Dash S. C, Singh N. Study of axisymmetric nature in 3D swirling flow in a cylindrical annulus with a top rotating lid under the influence of the axial temperature gradient or axial magnetic field. Journal of Thermal Engineering 2017;3(6) , Special Issue 6: 1588-1606. https://doi.org/10.18186/journal-of-thermalengineering.353737.

[16] Sarris I. E, Iatridis A. I, Dritselis C. D, Vlachos N. S. Magnetic field effect on the cooling of a low-Pr fluid in a vertical cylinder. Physics of fluids, 2010; 22, 017101-1, https://doi.org/10.1063/1.3291074.

[17] Rashidi M, Nasiri M, Khezerloo M, Laraqi N. Numerical investigation of magnetic field effect on mixed convection heat transfer of nanofluid in a channel with sinusoidal walls. J Magn Mater 2016;401:159-168. 
https://doi.org/10.1016/j.jmmm.2015.10.034.

[18] Sampath R, Zabaras N, Numerical Study of Convection in the Directional Solidification of a Binary Alloy Driven by the Combined Action of Buoyancy, Surface Tension, and Electromagnetic Forces. Journal of Computational Physics 2001;168: 384-411. https://doi.org/10.1006/jcph.2001.6706.

[19] Charmchi M, Zhang H, Li W, Faghri M. Solidification and melting of gallium in presence of magnetic fieldexperimental simulation of low gravity environment. 2004; IMECE2004-62365 Heat Transfer, 3: 581-589. https://doi.org/10.1115/IMECE2004-62365.

[20] Sankar M, Venkatachalappa M, Shivakumara I.S. Effect of magnetic field on natural convection in a vertical cylindrical annulus. International Journal of Engineering Science 2006; 44: 1556-1570. https://doi.org/10.1016/j.ijengsci.2006.06.004.

[21] Wrobel W, Wajs E. F, Szmyd J. S. Experimental and numerical analysis of thermo-magnetic convection in a vertical annular enclosure. International Journal of Heat and Fluid Flow 2010; 31: 1019-1031. https://doi.org/10.1016/j.ijheatfluidflow.2010.05.012.

[22] Afrand M, Toghraie D, Karimipour A, Wongwises S. A numerical study of natural convection in a vertical annulus filled with gallium in the presence of magnetic field. Journal of Magnetism and Magnetic Materials, 2017;430: 22-28. https://doi.org/10.1016/j.jmmm.2017.01.016.

[23] Bendjaghlouli A, Mahfoud B, Ameziani D.E. Magnetohydrodynamic flow in a truncated conical enclosure. Journal of Thermal Engineering 2019;5(2), Special Issue 9: 77-83. https://doi.org/10.18186/thermal.532133.

[24] Bakar N. A, Karimipour A, Roslan R. Effect of Magnetic Field on Mixed Convection Heat Transfer in a LidDriven Square Cavity. Hindawi Publishing Corporation Journal of thermodynamics 2016;http://dx.doi.org/10.1155/2016/3487182.

[25] Zahmatkesh I, Ardakani R. A. Effect of magnetic field orientation on nanofluid free convection in a porous cavity: a heat visualation study. Journal of Thermal Engineering 2020;6(1):170-186. https://doi.org/10.18186/thermal.672297.

[26] Patankar S.V. Numerical Heat Transfer and Fluid Flow. New York: Hemisphere Publishing Corp, Taylor \& Francis; 1980

[27] Shercliff A. The flow of conducting fluids in circular pipes under transverse magnetic fields. Journal of Fluid Mechanics 1956; 1: 644-666. https://doi.org/10.1017/S0022112056000421.

[28] Sarrisa I. E,Zikosa G. K, Grecosa A. P, Vlachos N. S. On the Limits of Validity of the Low Magnetic Reynolds Number Approximation in MHD Natural-Convection Heat Transfer. Numerical Heat Transfer, Part B,2006;50: 157-180. https://doi.org/10.1080/10407790500459403. 